\title{
Influence of the fibre/matrix interface on ageing mechanisms of glass fibre reinforced thermoplastic composites (PA-6,6, PET, PBT) in a hygrothermal environment
}

\author{
A. Bergeret*, L. Ferry, P. Ienny \\ Ecole des Mines d'Alès, Centre des Matériaux de Grande Diffusion, 6 avenue de Clavières, 30319 Alès Cedex, France
}

\begin{abstract}
A B S T R A C T
A study of the properties of short glass fibre reinforced thermoplastic composites based on poly(ethylene terephthalate), poly(butylene terephthalate) and polyamide-6,6 in an aggressive environment is reported. The influence of the fibre/matrix interface on the composite behaviour in a moist environment is especially studied. Competitive phenomena may explain differences observed according to the nature of the fibre surface treatment. Among them these characteristics may be an intrinsic fragility of some chemical interfacial bonds, the hydrophilicity of some chemical groups, the presence of long macromolecular chains neighbouring the interface or of a transcrystalline interfacial area.
\end{abstract}

PBT

\section{Introduction}

Owing to their excellent mechanical properties, composite materials have been widely used throughout the last four decades. Their use in hostile environment has given rise to studies devoted to the durability of their properties. In fact, as those materials are subjected to:

- environmental stresses such as high and/or low temperatures, moisture/water attack, UV exposure, saline atmosphere, presence of micro organisms;

- mechanical stresses due to long term mechanical stresses.

Different mechanisms may occur simultaneously according to the severity of the exposure conditions and led to a decrease in the composite lifetime:

- physical ageing inducing mechanical degradation including plasticization of the matrix and swelling and release of internal stresses,

\footnotetext{
* Corresponding author. Tel.: +33 466785 344; fax: +33 466785365 . E-mail address: anne.bergeret@ema.fr (A. Bergeret).
}

- chemical ageing inducing an irreversible chemical degradation such as hydrolysis of the matrix and the interphase and interfacial de-cohesion due to osmotic cracking.

This paper deal with the hygrothermal resistance of three commonly industrially used glass fibre reinforced thermoplastic composites: poly(ethylene terephthalate) (PET), poly(butylene terephthalate) (PBT) and polyamide-6,6 composites. In the literature most of studies have been focused on thermoset composites such as epoxies and unsaturated polyesters used for marine applications [1,2]. In this last case, the authors especially discussed interfacial de-cohesion induced by osmotic cracking damage. Nevertheless during this last decade considerable efforts have been devoted to understand the hygrothermal behaviour of glass fibre reinforced thermoplastic composites, such as polyimide $[3,4]$, polyetheretherketone (PEEK) [5], poly(phenylene sulfide) (PPS) [5], polyamides [6-8], and saturated polyesters (PET, PBT) [9-17].

In these studies authors generally focus either on one property (for example mechanical properties) or on one ageing factor (for example moisture) so that the extrapolation to industrial cases should be considered with caution as well as models proposed for lifetime prediction.

Moreover investigations mainly concern only two approaches: a macroscopic (millimetre) approach that gives information on macroscopic mechanical behaviour of the composite materials as 
a function of ageing time and a microscopic (nanometre) approach that gives details on molecular, morphological and microstructural evolutions with ageing time. Most of the time no relationship has been established between these two approaches.

Finally the prediction of the long term behaviour of composite materials remains difficult due to the lack of knowledge of the long term behaviour of the interface/interphase between the matrix and the fibre because of the small scale involved. Different approaches have been investigated through macroscopic samples representative of the interfacial zone $[18,19]$, through dynamic mechanical analyses [20] and through micromechanical tests such as pull-out, micro bond test [21-23], single fibre fragmentation test [24-26] and nano-indentation [27], but the extrapolation of the microscopic results to macroscopic behaviour should be considered in many cases with caution.

Therefore it is proposed in this paper to present a new multi scale approach. The objective of this approach is to create a link between the classical macroscopic (millimetre) approach (which gives information on macroscopic mechanical behaviour of the composite materials as a function of ageing time) and the microscopic (nanometre) approach (which gives details on molecular, morphological and microstructural evolutions with ageing time) by introducing an intermediate scale called mesoscopic (micron) scale that gives results on the local damage and potential stress accommodation.

\section{Materials and techniques}

\subsection{Materials}

Polymers used in this study were the following:

- terephthalate polyethylene PET $2153{ }^{\circledR}$ supplied by Dolder Co. (Basel, $\mathrm{CH}$ ),

- terephthalate polybutylene PBT Crastin ${ }^{\circledR}$ supplied by Dupont de Nemours Co. (Geneva, $\mathrm{CH}$ ),

- polyamide-6,6 PA-6,6 Zytel E101 ${ }^{\circledR}$ supplied by Dupont de Nemours Co. (Geneva, $\mathrm{CH}$ ).

Two kinds of glass fibres were incorporated in each polymer. The first was a glass fibre with a standard surface treatment which is compatible with the nature of the polymer matrix in which this fibre would be introduced. This fibre would be named $\mathrm{ST}_{\mathrm{PET}}, \mathrm{ST}_{\mathrm{PBT}}$ or $\mathrm{ST}_{\mathrm{PA6} 6}$ according to the nature of the polymer matrix. The second glass fibre is a glass fibre with a specific surface treatment which was formulated for an increased water resistance of the global composite in which the fibre will be incorporated. This fibre would be named $\mathrm{SP}_{\mathrm{PET}}$, $\mathrm{SP}_{\mathrm{PBT}}$ or $\mathrm{SP}_{\mathrm{PA} 6}$ according to the nature of the polymer matrix. All the glass fibres were supplied by Saint Gobain Vetrotex International Co. (Chambéry, France).

For this study, simplified surface treatments were used for glass fibres based only on two components, i.e. a coupling agent and a film former agent. It is well known through a huge amount of literature showed that the coupling agent which is in mainly cases an organosilane will react, on one side with the glass surface through siloxane functions, and on the other side, with the other components of the glass fibre sizing or with reactive groups of the matrix. A very small number of papers $[28,29]$ are published on film former agents, probably because of the reluctance of the glass fibres manufactures to reveal the composition of glass fibre surface treatments. Nevertheless it well known that the main role of film former agents is to protect the glass fibres during the fibre processing, to stick together the elementary filaments that form the glass fibre and to create chemical and/or physical linkages between the coupling agent and the polymer matrix. The composition of the different surface treatments used for this study are presented on Table 1.

The composite materials samples (ISO 527 type 1A dumbbells) were obtained through extrusion (Clextral BC21 twin screw extruder) and injection moulding (Sandretto Serie Otto AT). The glass fibres contents are in weight: $45 \%$ for PET composites, $15 \%$ for PBT composites and 30\% for PA-6,6 composites.

\subsection{Ageing tests}

Different sets of hygrothermal conditions were chosen according to the nature of the polymer matrix and to the final industrial applications of the composite materials. Indeed as polyester composites would be used for electronic households devices, the corresponding ageing condition for these composites is the immersion in water at $120^{\circ} \mathrm{C}$ in an autoclave under a pressure of 1.6 bars. Polyamide composites are used in some automotive applications such as under-the-hood devices, and especially antifreeze containers of the cooling automotive system. Therefore the ageing condition is the immersion in water at $135^{\circ} \mathrm{C}$ in an autoclave under a pressure of 2.8 bars. Samples were hung vertically in a Sanoclav MCS autoclave (20 l) and taken off at the chosen ageing time for the different characterisations. It can be noticed that these experimental ageing conditions are oxygen-free whereas real-life ageing will involve oxygen. Therefore following results may be lowered compared to the reality in some cases. The evolution of ageing as a function of oxygen concentration will be presented in a future paper.

\subsection{Techniques}

\subsubsection{Static and dynamic mechanical techniques}

Ultimate tensile properties (Adamel Lhomargy DY26 testing machine) and un-notched Charpy impact strengths (Zwick 5102) were investigated according to ISO 527 and ISO 75 International Standards respectively. Tensile tests were performed by using photomechanical techniques which lead to non-intrusive local and macro-homogeneous measurement of kinematic fields.

The dynamic mechanical properties were studied with a VA 815 Metravib RDS apparatus at a heating rate of $5{ }^{\circ} \mathrm{C} / \mathrm{min}$ over a temperature range from -150 to $230{ }^{\circ} \mathrm{C}$. The samples $\left(60 \times 10 \times 4 \mathrm{~mm}^{3}\right)$ were tested using an imposed frequency of $10 \mathrm{~Hz}$ and an oscillation amplitude of $10 \mu \mathrm{m}$ in the bending mode. The purpose of this analysis consisted in the determination of the main $\alpha$ relaxation characteristics for different ageing times.

\subsubsection{Photomechanical techniques}

The photomechanical technique is an optical method (white light source; high resolution CCD camera Kodak Megaplus 1.4 $1024 \times 1024$ scared and joined pixels) which allows the evaluation of in-plane kinematic field without contact with a surface geometrical pattern during a uniaxial tensile test (Dartec M1000/RE $100 \mathrm{kN}$ ). A digital image correlation software (CinEMA ${ }^{\circledR}$, Ecole des Mines d'Alès, France) allows the quantification of the Green Lagrange strain tensor at any point of the surface of the tested

Table 1

Surface treatments of the different glass fibres used in this study.

\begin{tabular}{|c|c|c|c|}
\hline & Glass fibres & Coupling agents & Film former agents \\
\hline \multirow[t]{3}{*}{ Standard glass fibres } & $\mathrm{ST}_{\mathrm{PET}}$ & Aminosilane & Polyurethane \\
\hline & $\mathrm{ST}_{\mathrm{PBT}}$ & Epoxysilane & Epoxy resin/amine agent \\
\hline & $\mathrm{ST}_{\mathrm{PA66}}$ & Aminosilane & Polyurethane \\
\hline \multirow{3}{*}{$\begin{array}{l}\text { Water resistance glass } \\
\text { fibres }\end{array}$} & SP PET & Aminosilane & Mixture of two epoxy resins \\
\hline & $\mathrm{SP}_{\mathrm{PBT}}$ & Aminosilane & Epoxy resin/epoxy agent \\
\hline & $\mathrm{SP}_{\mathrm{PA66}}$ & Aminosilane & Polyurethane/acrylic agent \\
\hline
\end{tabular}


sample. The image processing is based on a coarse-fine search method leading to the bi-dimensional displacement components with a sub-pixel accuracy. Applied to all the points that constitute the initial mesh, this treatment provides two dimensional kinematic field. According to the Cartesian coordinates system, gradient tensor and finally components of the in-plane strain tensor are evaluated. Hereafter the digital image processing is described for a pair of successive images. This procedure is applied for the whole set of images recorded during the tensile mechanical test. All the procedure details were already presented in previous papers [30-32].

The samples were previously countersunk in the thickness and painted (pulverization system) on their surface as an artificial pattern (Fig. 1). The studied composites being generally characterized by a viscoelastic behaviour, the mechanical tests includes relaxation step to exclude viscosity in the behaviour analysis. So the mechanical test includes four steps: (1) constant loading at $30 \mathrm{~N} / \mathrm{s}$; (2) relaxation during $900 \mathrm{~s}$ to avoid the temporal dependence of the stress; (3) unloading; (4) loading until sample fracture. Two different analysis could be carried on from the obtained results:

(1) A "macro-homogeneous" analysis from the third unloading step: A $(7.4 \mathrm{~mm})$ extensometer gauge was adopted for this first approach.

This step allows studying the elastic behaviour according the macro-homogeneous strain tensor measurements $\left(L_{\mathrm{xx}}, L_{\mathrm{xy}}, L_{\mathrm{yy}}\right)$. Assuming transverse isotropy of the material $\left(L_{\mathrm{xx}}=L_{\mathrm{zz}}\right)$ and small strain hypothesis (Equation (1)), the volume variation is obtained from the trace of the Lagrange's strain tensor. For an elastic response of the material established from the third unloading step, a theoretical relation between the volume variation and the nominal stress (also called First Piola Kirchhoff Stress) can be given by Equation (2). The deviations between experimental (Equation (1)) and theoretical (Equation (2)) curves should suggest the formation of cracks and cavities within the material. The longer an elastic behaviour is observed, the less damaged is the material.

$$
\left(\frac{\Delta V}{V_{0}}\right)_{\exp }=\sum \varepsilon_{\mathrm{ii}} \approx \sum L_{\mathrm{ii}}=2 L_{\mathrm{xx}}+L_{\mathrm{yy}}
$$

$\left(\frac{\Delta V}{V_{0}}\right)_{\text {theo }}=(1-2 \nu) L_{\mathrm{yy}}=\left(\frac{1-2 \nu}{E}\right) \sigma_{\mathrm{yy}}$

(2) A "local" analysis from the second loading step (fourth step): A $(0.6 \mathrm{~mm})$ local extensometric gauge was used to perform a statistical analysis of local strains, thanks to a mesh from the observed area of the sample. The extensometric gauge being smaller than the sample thickness, the previous assumption of transverse isotropy is not confirmed any more. Therefore a study of the surface variation (Equation (4)) seems to be more accurate. The image correlation treatment allows evaluating the standard deviation evolution of the surface strain. This local approach provides a representative parameter of the surface strain heterogeneity. Since significant differences between the strain levels can be observed, another parameter could be introduced, the coefficient of variation $\left(C_{\mathrm{v}}\right)$, which is a normalized expression of the surface standard deviation (Equation (4)). The lower this coefficient of variation is the more damaged material.

$\left(\frac{\Delta S}{S_{0}}\right)_{\exp } \approx L_{\mathrm{xx}}+L_{\mathrm{yy}}$

$C_{\mathrm{v}}=\operatorname{Sd}\left(\frac{\Delta S}{S_{0}}\right) /\left\langle\frac{\Delta S}{S_{0}}\right\rangle$

\subsubsection{Techniques for the characterisation of the microstructure}

Differential scanning calorimetry (Setaram DSC92) experiments were performed with a $10{ }^{\circ} \mathrm{C} / \mathrm{min}$ heating rate to determine thermal properties (melting and crystallization temperatures, crystallinity ratio).

Water uptakes after immersion for a given time were measured by weighing samples and taking into account the fibre content within the sample. To determine the soluble fraction, the ageing medium was taken and dried to evaporate water.

According to Pohl's method [33], carboxyl end groups in polyester composites and especially PET composites were determined through a specific titration at high temperature $\left(100{ }^{\circ} \mathrm{C}\right)$ using a methanolic sodium hydroxide solution $(0,1 \mathrm{~mol} /$ 1). PET was solubilized in a benzyl alcohol/chloroform solvent system.

Intrinsic viscosity was determined for polyester composites and especially PBT composites according to the ISO 1628/1 and ISO $1628 / 5$ International Standards in a dilute solution capillary viscometer (Ubbelohde, diameter $=0.76 \mathrm{~mm}$ ) of the dilution type (in a solvent phenol/tetrachloroethane $50 / 50$ wt\% at $25{ }^{\circ} \mathrm{C}$ ) by extrapolation to zero concentration of specific viscosity measurements obtained at four different concentration levels. A minimum of three measurements were performed for each solution.
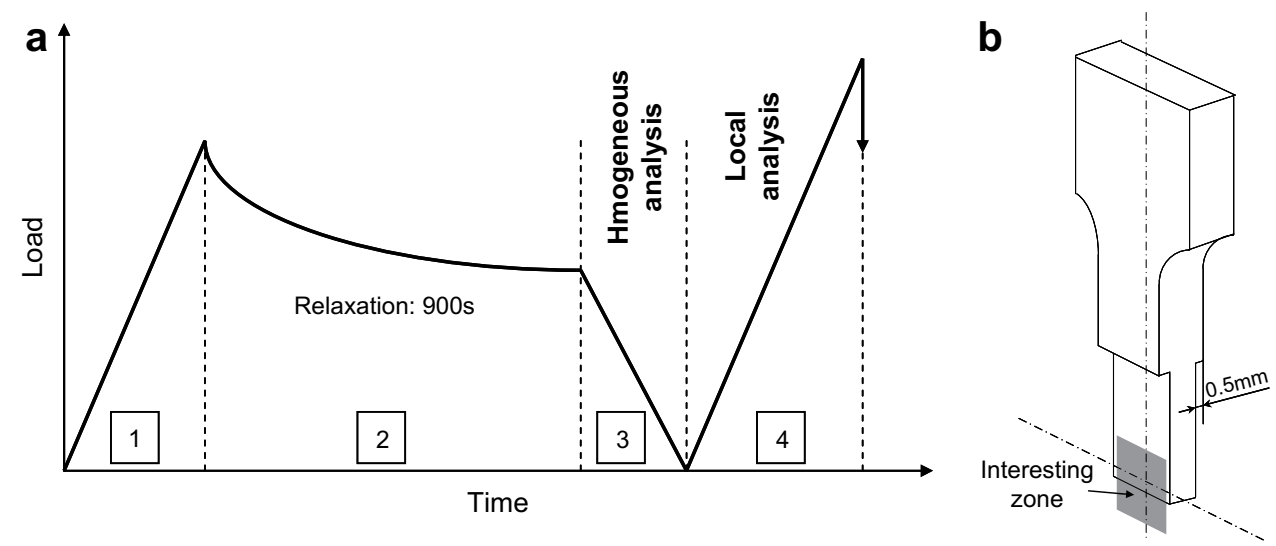

Fig. 1. Tensile test, scheme of the experimental loading steps (a) and scheme of specimen geometry (b). 
Observations of the fracture section of samples were investigated by using a Scanning Electron Microscope Jeol 35CF.

\section{Experimental section: results and discussion}

3.1. Influence of the polymer matrix on the ageing resistance of thermoplastic composite materials

The evolution of mechanical properties for the different composite materials as a function of ageing time is presented in Fig. 2. It can be observed a decrease in ultimate stress of about $90 \%$ for PET composites after an ageing time of $200 \mathrm{~h}$, of about $50 \%$ for PA-6,6 composites after an ageing time of $200 \mathrm{~h}$ and of about $80 \%$
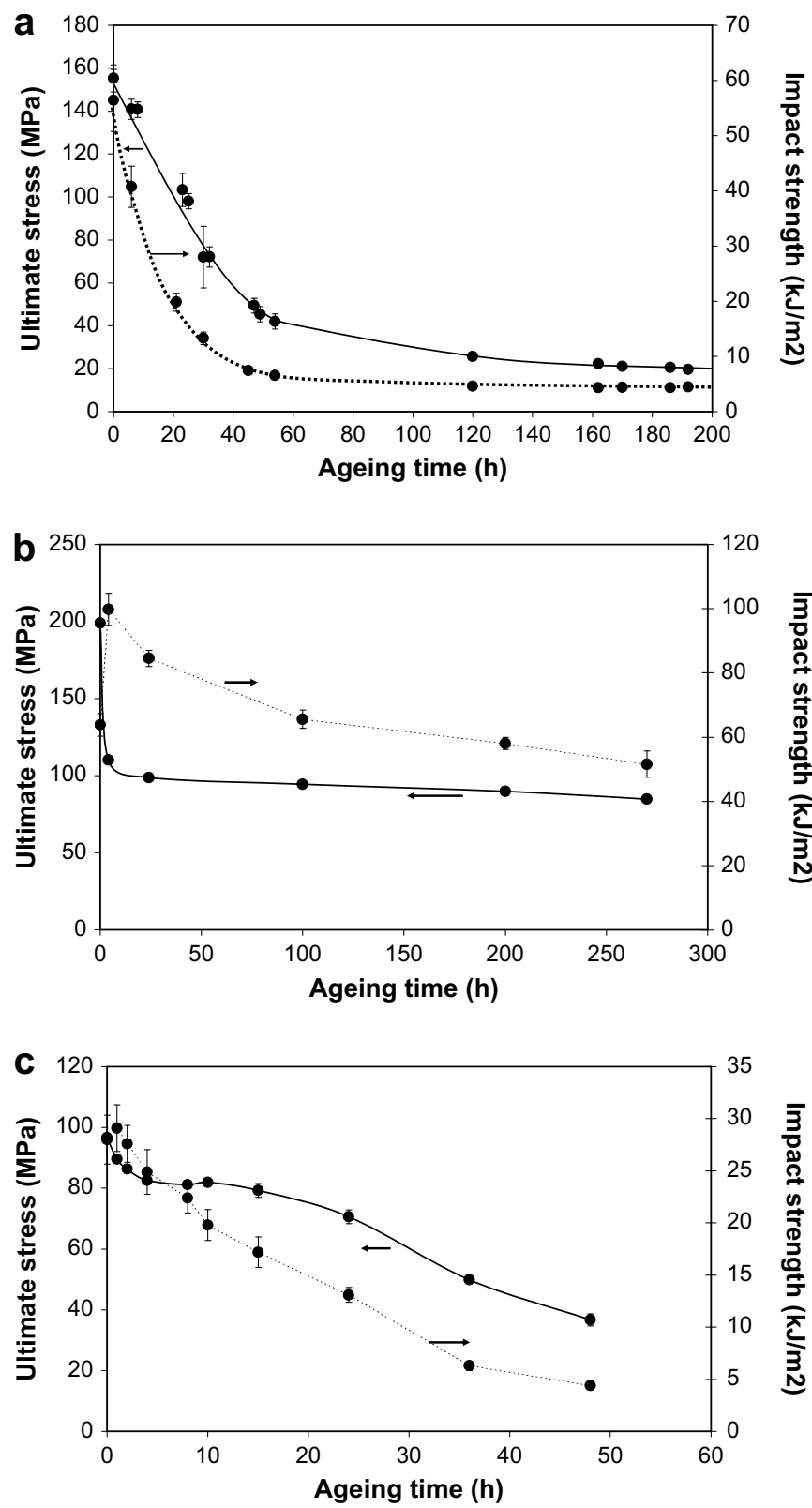

Fig. 2. Evolution of ultimate tensile stresses and impact strengths with ageing time for (a) PET composites (45 wt\% glass fibre); (b) PA-6,6 composites (30 wt\% glass fibre); (c) PBT composites (15 wt\% glass fibres); composites reinforced by ST/SP glass fibres (dashed line/full line). for PBT composites after an ageing time of $50 \mathrm{~h}$. As concerned impact properties, only PET composites did not show any plasticization revealed by a slight increase in impact strength for the early ageing times.

3.2. Influence of the fibre/matrix interface on the ageing resistance of thermoplastic composite materials

\subsubsection{PET composites}

3.2.1.1. Evolution of mechanical properties during ageing. Fig. 3 presents the changes of mechanical properties of PET composites reinforced by $\mathrm{ST}_{\mathrm{PET}}$ and $\mathrm{SP}_{\mathrm{PET}}$ glass fibres ( $45 \mathrm{wt} \%$ glass fibres). It can be observed for the composite reinforced by SPPET glass fibres a slighter decrease in ultimate stress and in impact strength with ageing time (especially for short ageing time below $40 \mathrm{~h}$ ) compared to composite reinforced by $\mathrm{ST}_{\mathrm{PET}}$ glass fibres. Fracture sections show also a residual adhesion for an ageing time of $86 \mathrm{~h}$ for the former composite.

\subsubsection{Evolution of microstructural characteristics during ageing}

3.2.1.2.1. Water absorption. Fig. 4 gives evidence of similar absorption kinetics for short ageing times whatever the glass fibre surface treatment. A different behaviour may occur for ageing times up to $16 \mathrm{~h}$ with a higher water absorption for the composite reinforced by $\mathrm{SP}_{\mathrm{PET}}$ glass fibres than for the composite reinforced by $\mathrm{ST}_{\mathrm{PET}}$ glass fibres may be because of a higher hydrophilicity of $\mathrm{SP}_{\mathrm{PET}}$ sizing.

In order to confirm this assumption, diffusion parameters have been determined as followed. When water equilibrium is observed for long ageing times, the composite behaviour could be described by Langmuir model for the diffusion. When it is not the case, Carter et al. [34] proposed an approximation of Langmuir's diffusion model (Equation (5)) by introducing two new parameters which are the probability water molecules should be trapped (parameter $\beta$ - Equation (6)) and un-trapped (parameter $\gamma$ - Equation (7)). As Fig. 4 shows that no equilibrium is reached for long ageing times, this last approach was applied and results are presented in Table 2. It can be observed that the probability the water molecules should be un-trapped within the composite is independent of the nature of the glass fibres. But it is noticed that the probability the water molecules should be trapped is twice as important for the composite reinforced by SPPET glass fibres. This result seems in good agreement with the previously higher hydrophilicity that has been observed (Fig. 4). This higher hydrophilicity could be due to the presence of an epoxy film former at the surface of the SPPET fibres that is more hydrophilic than a polyurethane film former (ST $\mathrm{PET}_{\mathrm{PET}}$ fibres).

$$
\begin{aligned}
& m_{\mathrm{t}}=m_{\infty}\left(1-\frac{\gamma}{\gamma+\beta} e^{-\beta t}\right) \\
& -\left(\frac{\mathrm{d} m_{\mathrm{t}}}{\mathrm{d} t}\right)^{-1} \frac{\mathrm{d}^{2} m_{\mathrm{t}}}{\mathrm{d} t^{2}} \approx \beta \\
& e^{-\beta t}\left[\beta\left(\frac{\mathrm{d} m_{t}}{\mathrm{~d} t}\right)^{-1} m_{\mathrm{t}}+1\right] \approx 1+\frac{\beta}{\gamma}
\end{aligned}
$$

with $m_{\mathrm{t}}, m_{¥}$ absorbed water weight for the ageing time $t$ and for long ageing times respectively.

3.2.1.2.2. Plasticization. Fig. 5 shows the damping curves obtained through dynamic mechanical experiments at two different ageing times ( $21 \mathrm{~h}$ and $45 \mathrm{~h}$ ) for PET composites according to the glass fibre surface treatments. It can be observed 

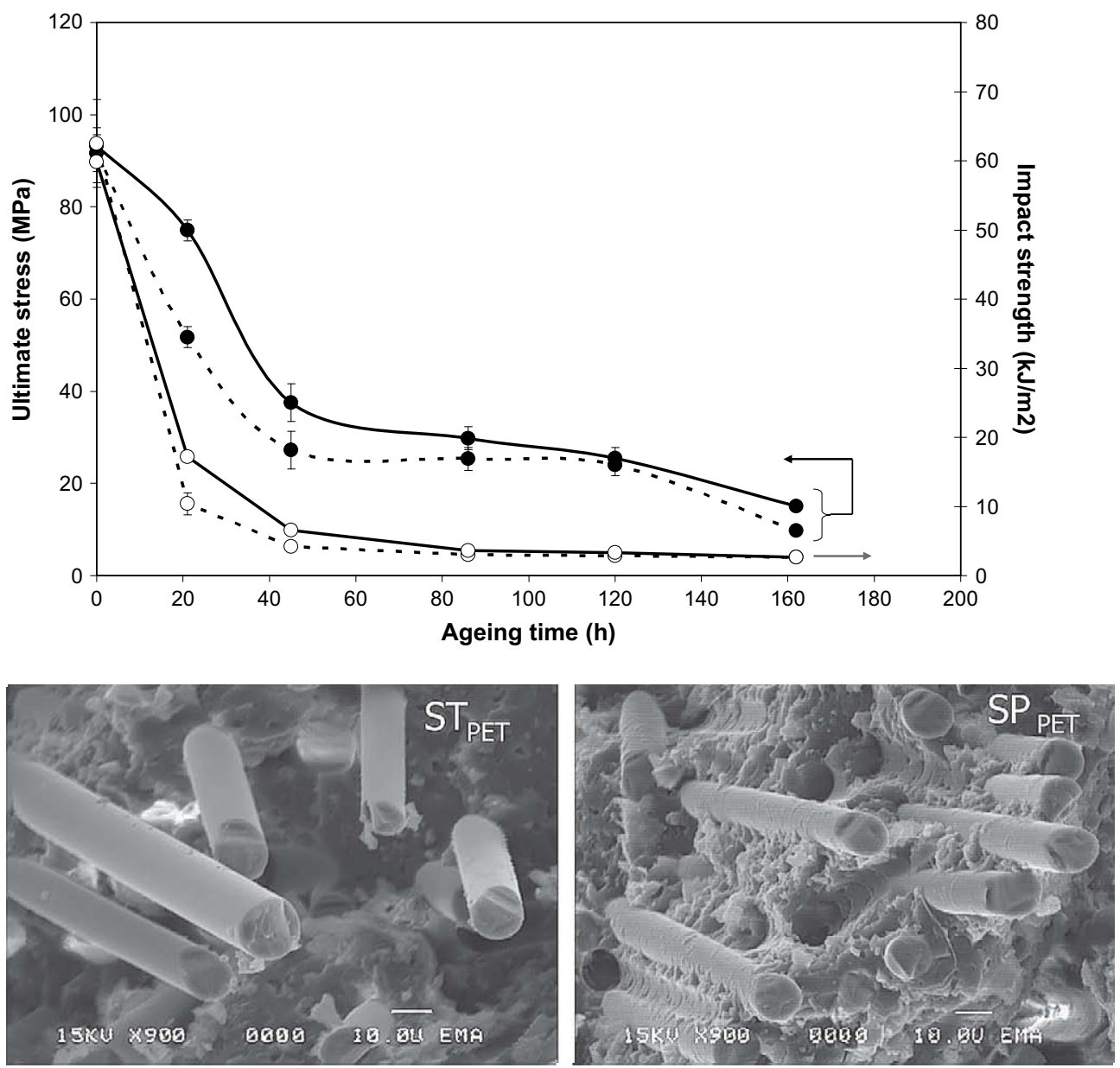

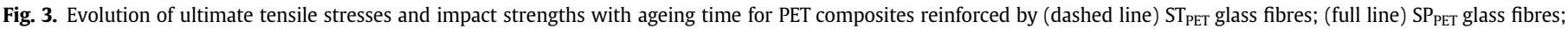
Fracture section for samples aged during $86 \mathrm{~h}$.

(i) a significant decrease towards lower temperatures (about $-16^{\circ} \mathrm{C}$ ) with ageing time of the main relaxation attributed to glass transition because of water absorption and of a plasticization of the polymer matrix;

(ii) a decrease in amplitude and a widening of the main relaxation related to a decrease in amorphous phase fraction because of oligomers extraction,

(iii) a slight lower amplitude of the main relaxation for the composite reinforced by $\mathrm{SP}_{\mathrm{PET}}$ glass fibres compared to the

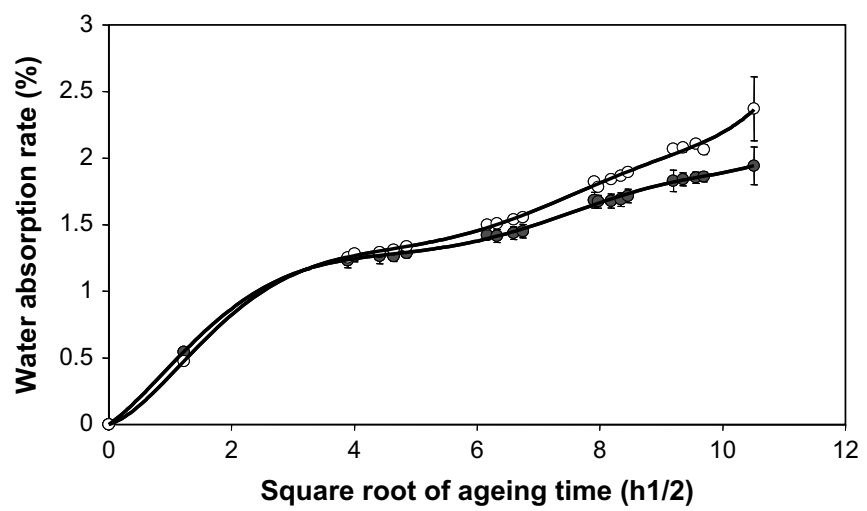

Fig. 4. Evolution of the water absorption rate with ageing time for PET composites reinforced by ( $\bullet \mathrm{ST}_{\mathrm{PET}}$ glass fibres; ( 0 ) $\mathrm{SP}_{\mathrm{PET}}$ glass fibres. composite reinforced by $\mathrm{ST}_{\mathrm{PET}}$ glass fibres for a given ageing time because of a higher hydrophilicity of the former.

3.2.1.2.3. Hydrolysis. Fig. 6 gives evidence of a rate of increase in acid end groups higher for the composite reinforced by $\mathrm{ST}_{\mathrm{PET}}$ fibres than the composite reinforced by $\mathrm{SP}_{\mathrm{PET}}$ fibres. This result seems in disagreement with the higher water absorption rate observed for the composite reinforced by SPPET fibres. To explain this result, it can be assumed that the higher fibre/matrix interface hydrophilicity (because of the presence of the epoxy functions of the film former agent) may protect the global hydrolysis of the core polymer matrix that may induce the damage of the composite.

3.2.1.2.4. Chemi-crystallization. Fig. 7 presents the changes of crystallinity and of melting temperature with ageing time according to the glass fibre surface treatments. Similar variations were observed with slightly higher crystallinity and melting temperature for the composite reinforced by $\mathrm{ST}_{\mathrm{PET}}$ fibres. This result is in agreement with the higher chemical degradation of the polymer

Table 2

Diffusion parameters according to Carter's model for PET composites reinforced by $\mathrm{ST}_{\mathrm{PET}}$ and $\mathrm{SP}_{\mathrm{PET}}$ glass fibres (very low standard deviations in accordance with reproducible results in water absorption rates).

\begin{tabular}{lll}
\hline & $\beta\left(\mathrm{h}^{-1}\right)$ & $\gamma\left(\mathrm{h}^{-1}\right)$ \\
\hline ST $_{\text {PET }}$ & 0.032 & 0.021 \\
SPET & 0.036 & 0.046 \\
\hline
\end{tabular}



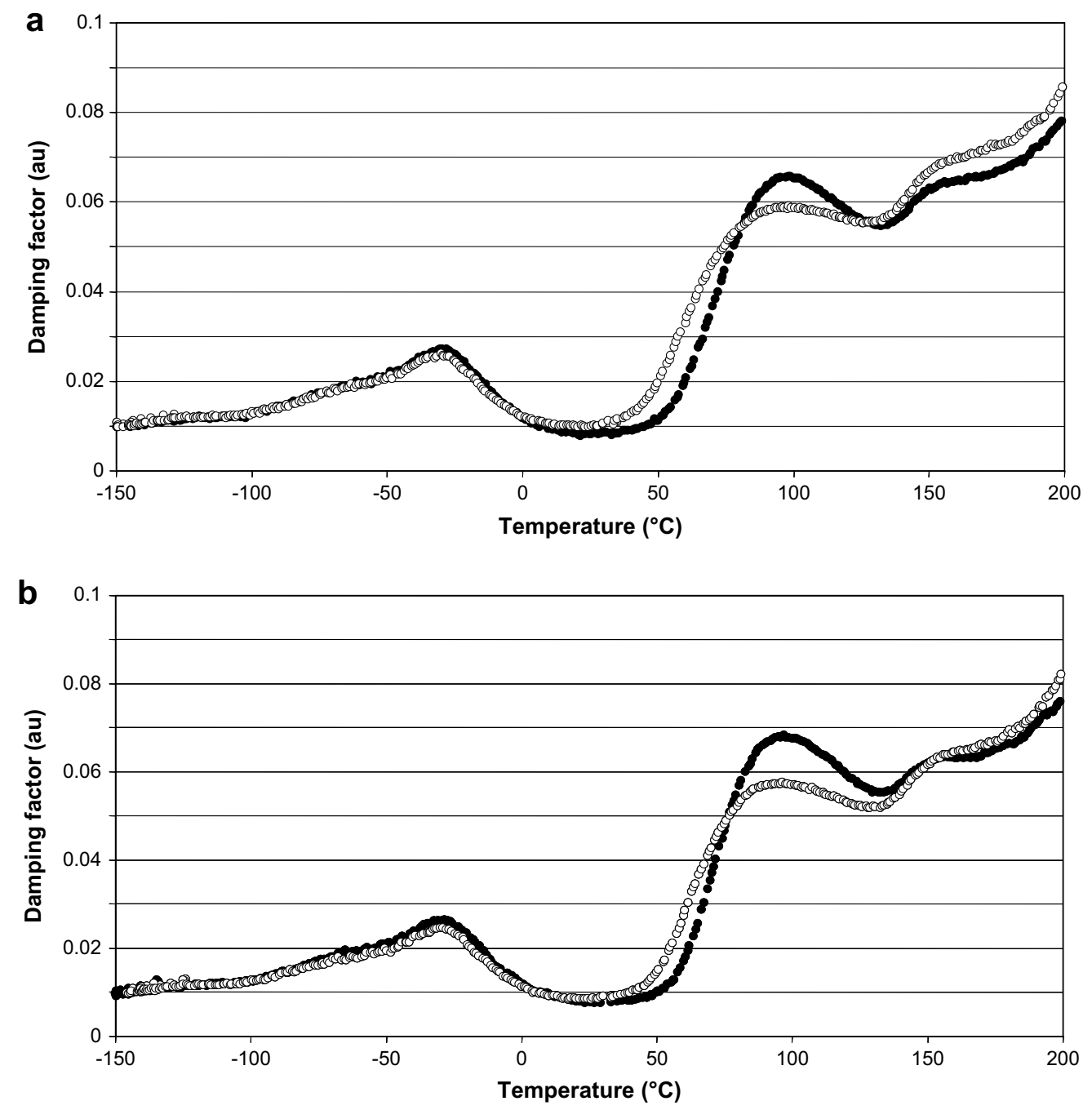

Fig. 5. Damping curves for PET composites reinforced by (a) $\mathrm{ST}_{\mathrm{PET}}$ glass fibres; (b) $\mathrm{SP}_{\mathrm{PET}}$ glass fibres aged during (0) $21 \mathrm{~h}$ and (o) $45 \mathrm{~h}$.

matrix of this composite (Fig. 5). The presence of degraded short chains may induce chemi-crystallization.

3.2.1.3. Assumptions concerning potential reactions at the fibre/ matrix interface during ageing. Initially, before ageing, the chemical reactions that may occur at the fibre/matrix interface are the following. For the composite reinforced by STPET fibres, the

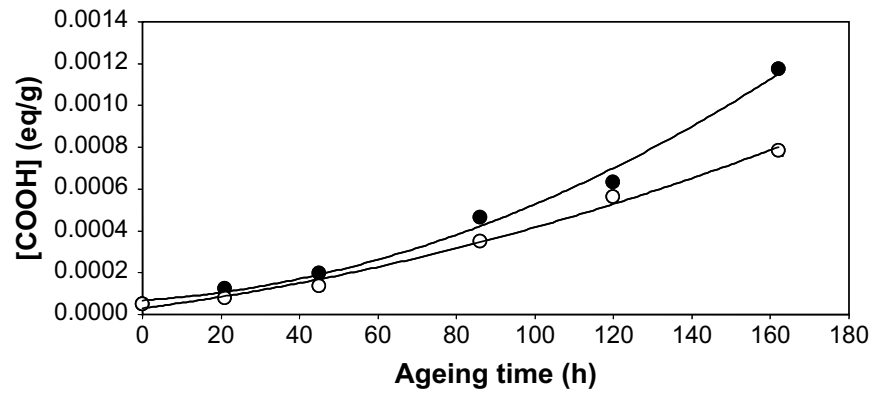

Fig. 6. Evolution of the acid end groups rate with ageing time for PET composites reinforced by ( $\bullet$ ) $\mathrm{ST}_{\mathrm{PET}}$ glass fibres; ( $\left.\mathrm{O}\right) \mathrm{SP}_{\mathrm{PET}}$ glass fibres. potential reactions are (i) reactions between the isocyanate functions of polyurethane film former and the amine functions of the aminosilane coupling agent leading to diamide groups, and (ii) reactions between isocyanate functions of polyurethane film former and the acid or alcohol functions of the PET matrix leading to amide or ester amide groups respectively. For the composite reinforced by $S_{\text {PET }}$ fibres, the potential reactions are (i) reactions between the epoxy functions of the film former and the amine functions of the coupling agent leading to alcohol amine groups, and (ii) reactions between the epoxy functions of the film former and the acid or alcohol functions of the PET matrix leading to alcohol ester or alcohol ether groups respectively.

In the presence of water diffusing within the polymer matrix and at the fibre/matrix interface, the hydrolysis reactions may be significantly different according to the nature of the glass fibre surface treatment. For the composite reinforced by ST $\mathrm{PET}_{\mathrm{PET}}$ fibres, the amide and ester groups present at the fibre/matrix are known as hydrolytically fragile and may be broken in presence of water molecules. For the composite reinforced by SPPET fibres, the presence of hydroxyl groups (alcohol functions) at the fibre/matrix interface makes it very hydrophilic. This result has been confirmed by water absorption rate measurements (Fig. 4). Nevertheless the functions are stable towards water molecules so that the chemical 

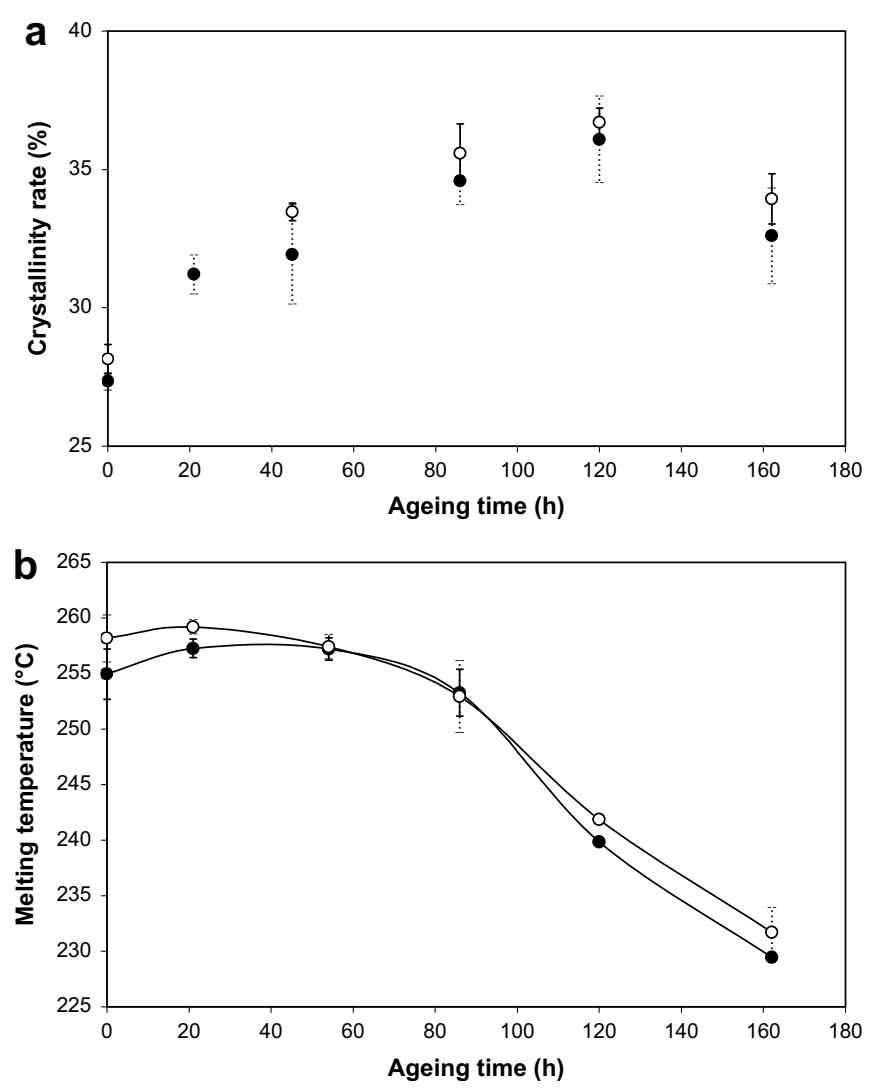

Fig. 7. Evolution of (a) the crystallinity rate; (b) melting temperature with ageing time

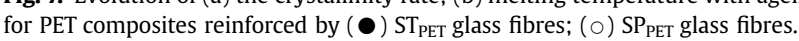

degradation of the global composite is not very important (Figs. 3 and 6). If residual epoxy functions (from the film former) are still present at the fibre/matrix interface, glycol end groups can be obtained in presence of water that does not degrade the efficiency of the interface.

3.2.1.4. Evolution of material damage during ageing. As described in the "Techniques" section, two kinds of measurements could be investigated based on photomechanical analysis, i.e. a macrohomogeneous analysis and a local analysis.

3.2.1.4.1. Macro-homogeneous analysis. Fig. 8 shows the change of volume variation as a function of longitudinal strain $L_{y y}$ for unaged and aged ( $76 \mathrm{~h}$ ) PET composites according to the nature of the surface treatment of the glass fibres.

For unaged composites, the damage is only due to the mechanical test. In this case, slight differences in the behaviour could be observed according to the surface treatment as the experimental volume variation becomes higher than the analytical one beyond a higher longitudinal strain $L_{\mathrm{yy}}$ for the composite reinforced by $\mathrm{SP}_{\mathrm{PET}}$ fibres $(0.020)$ than for the composite reinforced by $\mathrm{ST}_{\mathrm{PET}}$ fibres $(0.015)$.

For aged composites, the damage is mainly due to also the hygrothermal ageing, so that the volume variation increased very fast with the applied longitudinal strain. Therefore no significant differences could be observed between both aged composites.

3.2.1.4.2. Local analysis. Fig. 9 presents the evolution of the coefficient of variation (as defined in the "Techniques" section) as a function of longitudinal strain $L_{\mathrm{yy}}$ for unaged and aged (76 h) PET composites according to the nature of the surface treatment of the glass fibres. First it can be observed that aged composites present a lower coefficient of variation than unaged ones. As this parameter is related to the surface strain heterogeneity, this result means a decrease in the ability for aged materials to accommodate their internal stresses, especially stresses located at the fibre/matrix interface. Secondly, a lower local strain activity can be observed for the composite reinforced by $\mathrm{ST}_{\mathrm{PET}}$ fibres, because of a more important interfacial de-cohesion for that composite.

\subsubsection{PBT composites}

3.2.2.1. Evolution of mechanical properties during ageing. Fig. 10 presents the change of mechanical properties of PBT composites reinforced by $\mathrm{ST}_{\mathrm{PBT}}$ and $\mathrm{SP}_{\mathrm{PBT}}$ glass fibres (15 wt\% glass fibres). Better ageing resistance can be observed for the composite reinforced by SРРВT fibres. An increase in impact strength relative to plasticization at the very early ageing times can be observed especially for the composite reinforced by $\mathrm{ST}_{\mathrm{PBT}}$ fibres.

3.2.2.2. Evolution of microstructural characteristics during ageing. Fig. 11 gives evidence of a lower water absorption rate for the composite reinforced by the SP $\mathrm{PBT}$ fibres than for the composite

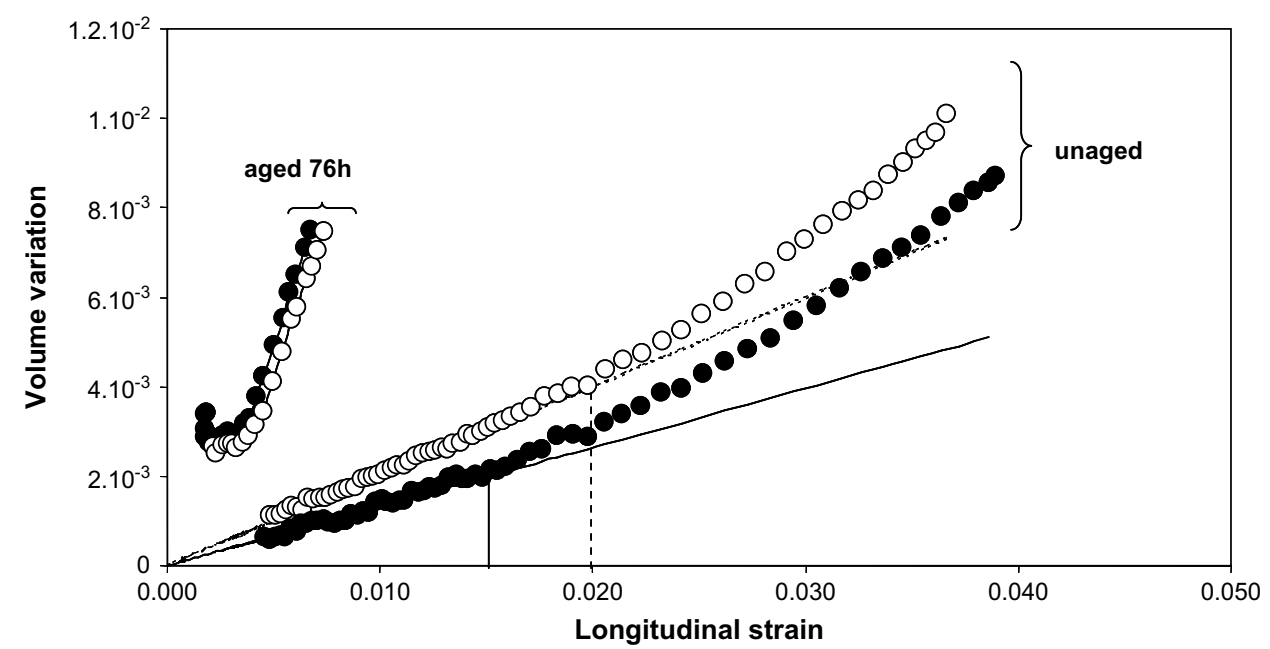

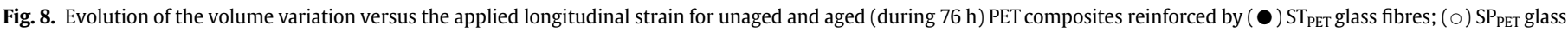
fibres. 


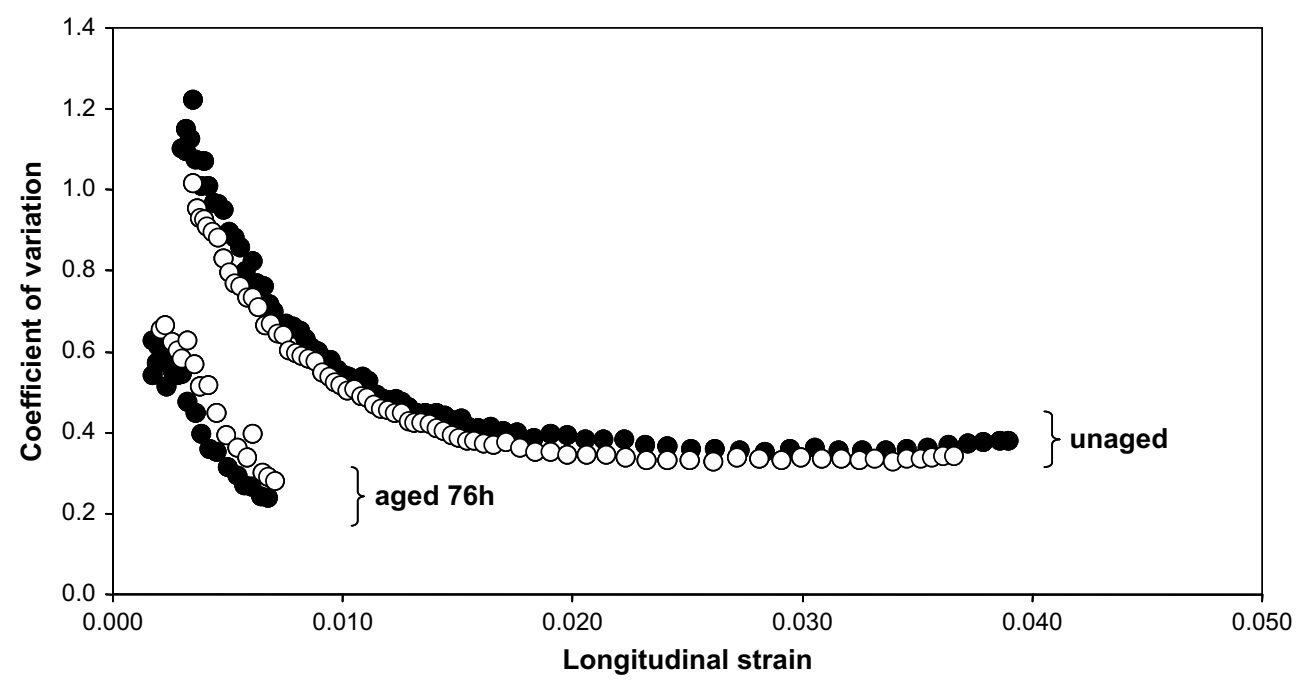

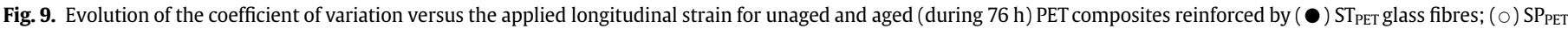
glass fibres.

reinforced by the $\mathrm{ST}_{\mathrm{PBT}}$ fibres except for very early ageing times because polymer plasticization (Fig. 10). Fig. 11 shows also that initial crystallinity rates (before ageing) are significantly different with a higher rate for the composite reinforced by $\mathrm{ST}_{\mathrm{PBT}}$ fibres even if the differences diminished with increased ageing time. This higher initial crystallinity rate could be related to the presence of short macromolecular chains for that composite as it is shown through intrinsic viscosity measurements. Indeed a drastic decrease in intrinsic viscosity with ageing times can be observed for composites as no variations were observed for PBT matrix.

3.2.2.3. Assumptions concerning potential reactions at the fibre/ matrix interface during ageing. Initially, before ageing, the chemical reactions that may occur at the fibre/matrix interface are the followings. For the composite reinforced by $\mathrm{ST}_{\mathrm{PBT}}$ fibres, the potential reactions are reactions between on one side the epoxy functions of epoxy film former and epoxysilane coupling agent and on the other side the amine functions of film former leading to alcohol amine groups. For the composite reinforced by $\mathrm{SP}_{\mathrm{PBT}}$ fibres, the potential reactions are (i) reactions between the epoxy functions of the film former and the amine functions of the coupling agent leading to

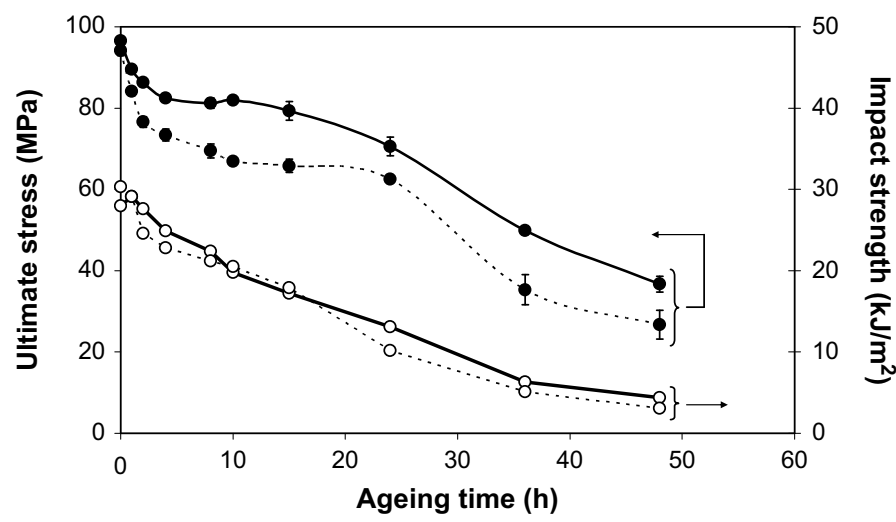

Fig. 10. Evolution of ultimate tensile stresses and impact strengths with ageing time for $\mathrm{PBT}$ composites reinforced by (dashed line) $\mathrm{ST}_{\mathrm{PBT}}$ glass fibres; (full line) $\mathrm{SP}_{\mathrm{PBT}}$ glass fibres. alcohol amine groups, and (ii) reactions between the epoxy functions of the film former and the acid or alcohol functions of the PBT matrix leading to alcohol ester or alcohol ether groups respectively.

In the presence of water diffusing within the polymer matrix and at the fibre/matrix interface, the absence of chemical linkages between the components of the glass fibre surface treatment and the PBT matrix for the composite reinforced by $\mathrm{ST}_{\mathrm{PBT}}$ fibres makes this fibre/matrix interface and therefore this composite fragile in a hygrothermal environment.

\subsubsection{PA-6,6 composites}

3.2.3.1. Evolution of mechanical properties during ageing. Fig. 2 presents the changes of mechanical properties of PA-6,6 composites reinforced by $\mathrm{ST}_{\mathrm{PA6}}$ and SPA66 glass fibres (30 wt\% glass fibres). It can be observed a better ageing resistance for the composite reinforced by SPA66 fibres. An increase in impact strength relative to plasticization at the early ageing times can be observed especially for the composite reinforced by STPA66 fibres.

3.2.3.2. Evolution of microstructural characteristics during ageing. Fig. 12 gives evidence of a fast water diffusion within the PA-6,6 composites according to Fick laws (presence of a plateau for long ageing times). The comparison between both composites shows that the composite reinforced by SPPA66 fibres presents lower water content than the composite reinforced by ST PA66 fibres. Moreover the solubilized fraction is lower for the former than for the later with a constant difference of about $0.15 \%$.

Moreover no significant variation of the melting enthalpy, or of the crystallinity rate, with ageing time was observed whatever the glass fibre surface treatment (Fig. 13).

Thermomechanical properties, and especially the damping factor, of both PA-6,6 composites are presented in Fig. 14. The following items can be observed:

(1) Unaged PA-6,6 presents three mechanical relaxations, named $\alpha$ (at about $\left.80^{\circ} \mathrm{C}\right), \beta$ (at about $-50^{\circ} \mathrm{C}$ ) and $\gamma\left(\right.$ at about $-120^{\circ} \mathrm{C}$ ), which are related to more and more local motions of macromolecular chains;

(2) After ageing, (i) the $\gamma$ relaxation is shifted towards lower temperatures (below $-150{ }^{\circ} \mathrm{C}$ ) in good agreement with literature [35], (ii) the $\beta$ relaxation is shifted from $-40{ }^{\circ} \mathrm{C}$ to $-80^{\circ} \mathrm{C}$ 

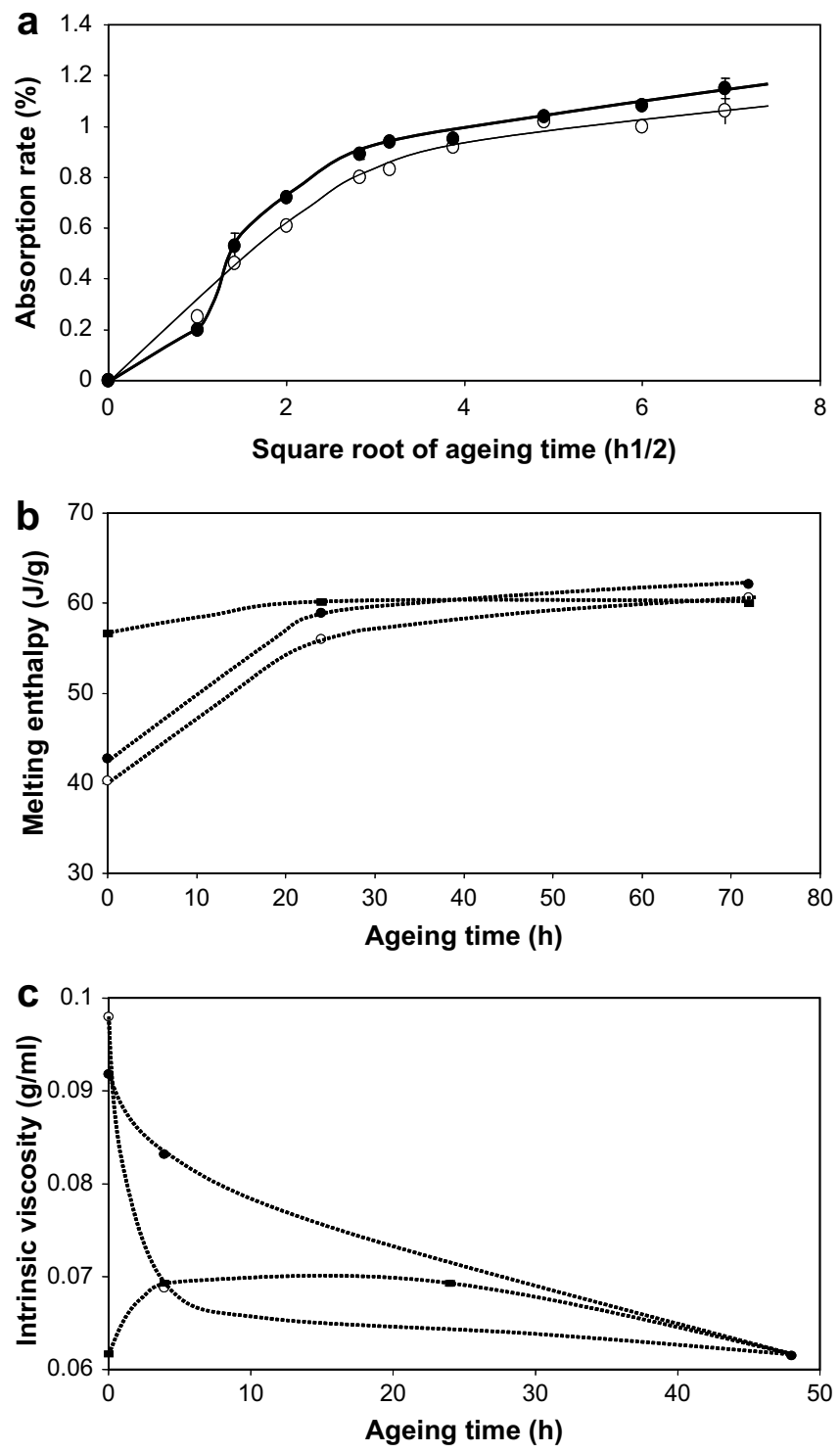

Fig. 11. Evolution of (a) water absorption rate; (b) melting enthalpy; (c) intrinsic viscosity with ageing time for PBT matrix ( $\boldsymbol{\square})$ and for composites reinforced by $\mathrm{ST}_{\mathrm{PBT}}$ glass fibres and $(0) \mathrm{SP}_{\mathrm{PBT}}$ glass fibres.

with a decrease in magnitude; (iii) the $\alpha$ relaxation is divided in two relaxations located at $0{ }^{\circ} \mathrm{C}$ and $100{ }^{\circ} \mathrm{C}$, which were attributed by Murthy [36] to water diffusion respectively within intra-spherulitic (strong linked water molecules) and inter-spherulitic (weak linked water molecules) phases.

(3) The glass fibre surface treatment has no significant influence on mechanical relaxations characteristics except a slight shift towards low temperatures of all relaxations in the case of $\mathrm{ST}_{\text {PA66 }}$ fibres.

3.2.3.3. Assumptions concerning potential reactions at the fibre/ matrix interface during ageing. Initially, before ageing, the chemical reactions that may occur at the fibre/matrix interface are the followings. For the composite reinforced by $\mathrm{ST}_{\mathrm{PA} 6}$ fibres, the potential reactions are (i) reactions between the isocyanate functions of polyurethane film former and amine functions of coupling agent leading to diamide groups, and (ii) reactions between the isocyanate functions of polyurethane film former and acid
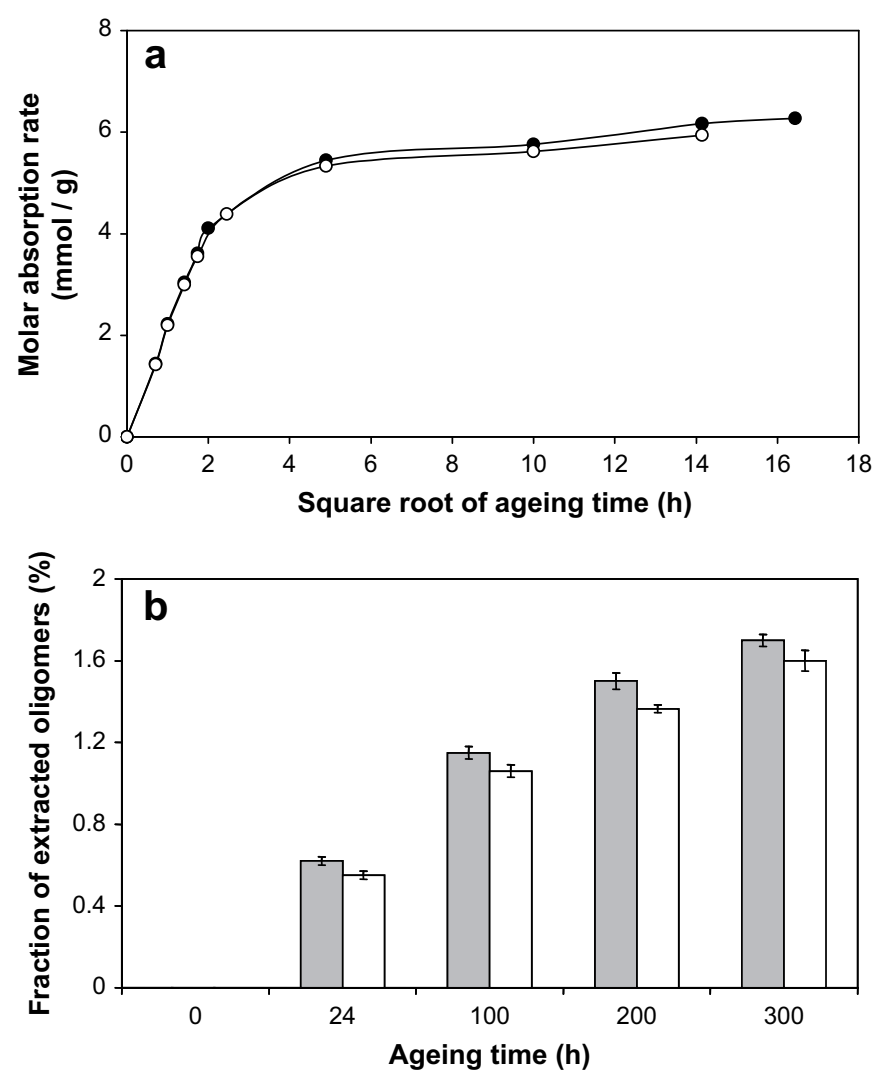

Fig. 12. Evolution of (a) the water absorption rate and (b) the fraction of extracted oligomers with ageing time for PA-6,6 composites reinforced by ( - grey bars) ST PA66 glass fibres and ( $\mathrm{-}-$ white bars) $\mathrm{SP}_{\mathrm{PA66}}$ glass fibres.

functions of PA-6,6 matrix leading to amide groups. For the composite reinforced by SPA66 fibres, the potential reaction is an amidation reaction between the acrylic agent and the amine end functions of PA-6,6 matrix.

In the presence of water diffusing within the polymer matrix and at the fibre/matrix interface, it can be established by classifying from the more to the less stable chemical bonds in presence of water which is: alkyl $>$ amide $\sim$ urethane $>$ ester. Even if the acrylic agent presents an ester function, this one is a pendant group, so that the main chain is not damaged by hydrolysis. For the composite reinforced by SPPA66 fibres, the complementary

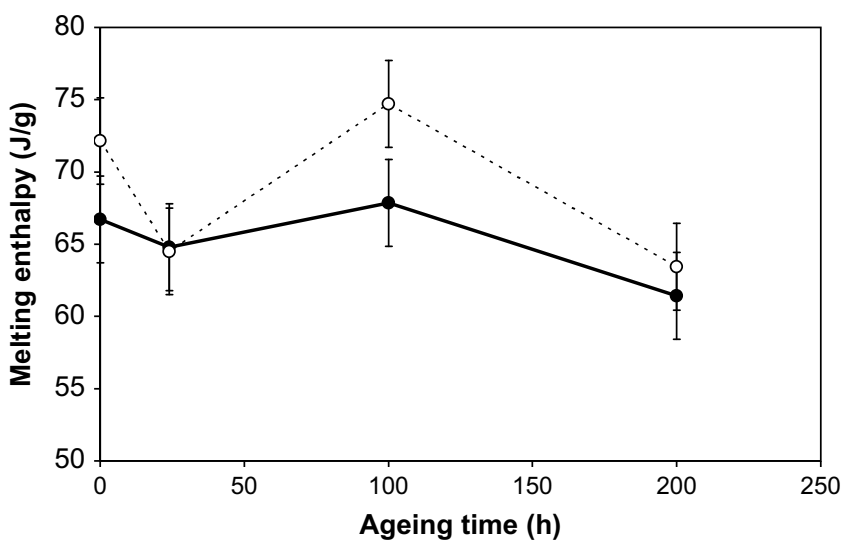

Fig. 13. Evolution of the melting temperature with ageing time for PA-6,6 composites reinforced by (๑) $\mathrm{ST}_{\mathrm{PA} 66}$ glass fibres and $(0) \mathrm{SP}_{\mathrm{PA66}}$ glass fibres. 


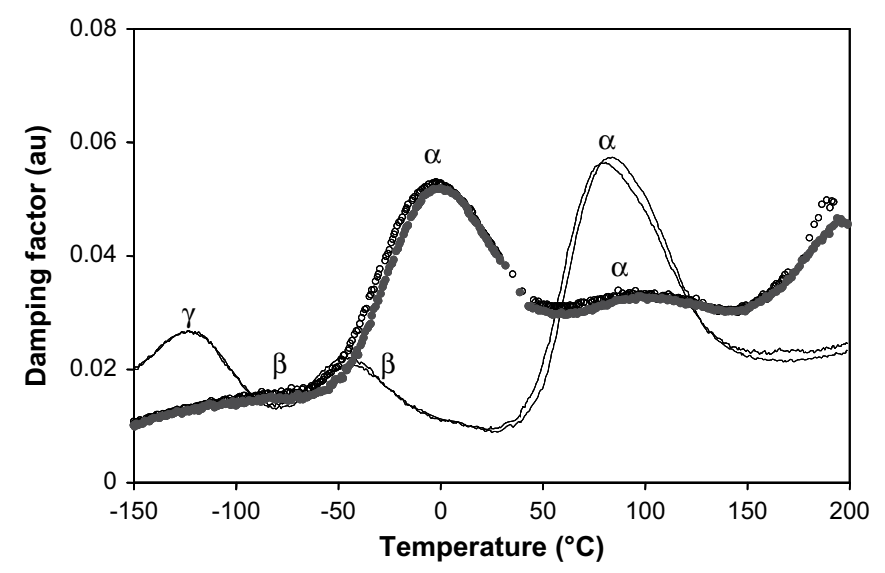

Fig. 14. Thermomechanical properties (damping factor) of unaged (full line) and aged during $165 \mathrm{~h}$ (symbols) of PA-6,6 composites reinforced by ( $)$ ST $_{\text {PA66 }}$ glass fibres and (०) SPAa66 glass fibres.

amidation reaction may increase even more the resistance of the fibre/matrix interface of the material.

\section{Conclusions}

This study gives evidence that the fibre/matrix interface plays an essential role in the behaviour of thermoplastic composites in a hygrothermal environment. Significant differences were observed according to the nature of the fibre surface treatment. Various phenomena that are in competition may occur such as the intrinsic brittleness of some chemical interfacial linkages, the hydrophilicity of some chemical functions, the presence of more or less long macromolecular chains at the interface or of an interfacial transcrystalline area.

\section{Acknowledgments}

The authors are indebted to Saint Gobain Vetrotex International Co. (Chambéry, France) and especially to M. Michel Arpin and M. Jean Philippe Gasca, for materials, helpful discussions and financial support in carrying out a part of this work. The authors are also grateful to Ms Isabelle Pires (ageing of PA-6,6 composites), Ms Marie Pierre Foulc (ageing of PET composites) and M. Bruno Abadie (ageing of PBT composites), students who were involved in this research.

\section{References}

[1] Gautier L, Mortaigne B, Cellenger V. Interface damage study of hydrothermally aged polyester matrix. Polymer 2000;41:2481-90.

[2] Pauchard V, Grosjean F, Campion-Boulharts H, Chateauminois A Application of stress corrosion cracking model to an analysis of the durability of glass epoxy composites in wet environments. Compos Sci Technol 2002;62:493-8.

[3] Yang DK, Koros WJ, Hopfenberg HB, Stannett VT. The effects of morphology and hygrothermal aging on water sorption and transport in Kapton ${ }^{\circledR}$ polyimide. J Appl Polym Sci 1986;31(6):1619-29.

[4] Han MH, Nairn JA. Hygrothermal aging of polyimide matrix composite laminates. Compos Part A Appl S 2003;34(10):979-86.

[5] Chen Chi MM, Chang Lun L, Min Jong C, Nyan Hwa T. Effect of physical aging on the toughness of carbon fiber reinforced poly(ether ether ketone) and poly(phenylene sulphide) composites. Polym Compos 1992;13(6):441-7.

[6] Mohd Ishak ZA, Ishiaku US, Karger Kocsis J. Microstructure related fracture behaviour of injection moulded short fibre reinforced polyarylamide in dry and wet state. J Mater Sci 1998;33(13):3377-89.
[7] Mohd Ishak ZA, Berry JP. Hygrothermal aging studies of short carbon fiber reinforced nylon 6.6. J Appl Polym Sci 1994;51(13):2145-55.

[8] Akay M. Moisture absorption and its influence on the tensile properties of glass-fibre reinforced polyamide 6.6. Polym Polym Compos 1994;2(6):349-54.

[9] Mohd Ishak ZA, Lim NC. Effect of moisture on the tensile properties of short glass fiber reinforced poly(butylene terephthalate). Polym Eng Sci 1994;34(22):1645-55.

[10] Czigany T, Mohd Isak ZA, Karger Kocsis J. Effect of hygrothermal aging on the fracture and failure behaviour in short glass reinforced, thoughned poly (butylene terephthalate) composites. Polym Compos 1996;17(6):900-9.

[11] Mohd Ishak ZA, Ariffin A, Senawi R. Effects of hygrothermal aging and a silane coupling agent on the tensile properties of injection molded short glass fiber reinforced poly(butylene terephthalate) composites.

[12] Barany T, Karger Kocsis J, Czigany. Effect of hygrothermal aging on the essential work of fracture response of amorphous poly(ethylene terephthalate) sheets. Polym Degrad Stab 2003;82(2):271-8.

[13] Mac Mahon W, Birsdall HA, Johnson GR, Camilli CT. Degradation studies of polyethylene terephthalate. J Chem Eng Data 1959;4(1):57-79.

[14] Ravens DAS, Ward IM. Chemical reactivity of polyethylene terephthalate. Trans Far Soc 1961:57:150-9.

[15] Golike RC, Lasoski Jr SW. Kinetics of hydrolysis of polyethylene terephthalate films. J Phys Chem 1960;64:895-8.

[16] Ballara A, Verdu J. Physical aspects of the hydrolysis of polyethylene terephthalate. Polym Degrad Stab 1989;26:361-74.

[17] Launay A, Thominette F, Verdu J. Hydrolysis of poly(ethylene terephthalate) a kinetic study. Polym Degrad Stab 1994;46:319-24.

[18] Salmon L, Thominette F, Pays MF, Verdu J. Hydrolytic aging of polysiloxane networks modeling the glass fiber epoxy-amine interphase. Polym Compos 1999;20(6):715-24.

19] Salmon L, Thominette F, Pays MF, Verdu J. Hydrolytic degradation of model networks simulating the interfacial layer silane coupled epoxy/glass composites. J Compos Sci Technol 1997;57(8):1119-27.

[20] Zinck P, Gerard JF. Are microcomposites realistic models of the fibre/matrix interface? Physico-chemical approach. Polymer 2001;42(15):6641-50.

[21] Gaur U, Miller B. Effects of environmental exposure on fiber epoxy interfacial shear strength. Polym Compos 1990;11(4):217-22.

[22] Biro DA, Pleizer G, Deslandes Y Application of the microbond technique: effects of hygrothermal exposure on carbon fiber/epoxy interfaces. Compos Sci Technol 1993;46(3):293-301.

[23] McDonough WG, Antonucci JM, Jianmei H, Shimada Y, Chiang MYM Schumacher GE. A microshear test to measure bond strengths of dentinpolymer interfaces. Biomaterials 2002;23(17):3603-8.

[24] Schutte CL, McDonough WG, Shioya M, McAuliffe M, Greenwood M. The use of a single fibre fragmentation test to study environmental durability of interfaces/interphases between DGEBA/MPDA epoxy and glass fibre: the effect of moisture. Composites 1994;25(7):617-24.

25] Pawson D, Jones FR. The effect of sodium ions on the stability of the interpahse region of glass fibre reinforced composites. J Adhesion 1995;52(1-4):187-207.

[26] Wagner HD, Lustiger A. Effect of water on the mechanical adhesion of the glass/epoxy interface. Composites 1994;25(7):613-6.

[27] Hodzic A, Kim JK, Lowe AE, Stachurski ZH. Nano-indentation and nano-scratch of polymer/glass interfaces. II: model of interphases in water aged composite materials. Compos Sci Technol 2001;42(13):5701-10.

[28] Thomason JL. The interface region in glass fibre reinforced epoxy resin composites. III. Characterization of fibre coatings and the interphase. Titre. Composites 1995;26(7):487-98.

[29] Bergeret A, Bozec MP, Quantin JC, Crespy A, Gasca JP, Arpin M. Study of interphase in glass fiber reinforced poly(butylene terephthalate) composites. Polymer Composites 2004;25(1):12-25.

[30] Giton M, Ienny P, Piques R. Viscous hyper-elastic behaviour characterisation of a silicone-rubber: inverse problem resolution based on measurements by digital image correlation. Châlons-en-Champagne (France): Comptest; 2003.

[31] Laraba Abbes F, Ienny P, Piques R. A new tailor-made methodology for the mechanical behaviour analysis in rubber like materials: I. Kinematics measurements using a digital speckle extensometry. Polymer 2003;44: 807-20.

[32] Foulc MP, Bergeret A, Ferry L, Ienny P, Crespy A. Study of hygrothermal ageing of glass fibre reinforced PET composites. Polym Degrad Stab 2005;89:461-70.

[33] Pohl HA. Determination of carboxyl end groups in a polyester, polyethylene terephthalate. Anal Anal 1954;26(10):1614-6.

[34] Carter HG, Kibler KG. Langmuir type model for anomalous moisture diffusion in composite resins. J Compos Mater 1978;12:118-31.

[35] Adamczak L. Etude du vieillissement hygrothermique de trois thermoplastiques à l'état massique et renforcés de fibres de verre continues. PhD thesis 1995. Ecole des Mines de Paris (France).

[36] Murthy NS, Akkapedi MK. Analysis of lamellar structure in semicrystalline polymers by studying the absorption of water and ethylene glycol in nylons using small angle neutron scattering. Macromolecules 1998;31:142-52. 